\title{
CONTRIBUiçÃo DO JOGO DIDÁTICO “CONHECENDO OS INVERTEBRADOS" PARA O ENSINO DE BIOLOGIA
}

\author{
CONTRIBUTION OF THE DIDACTIC GAME "KNOWING THE \\ INVERTEBRATES" FOR THE TEACHING OF BIOLOGY
}

DOI: http://dx.doi.org/10.23926/RPD.2526-2149.2020.v5.n1.p325-343.id621

\section{Adriano Marcos \\ Romano \\ Mestre em Ensino de \\ Biologia \\ (ProfBio/UNEMAT) \\ Professor no Centro \\ Universitário São Lucas \\ (UNISL) \\ adriano.romano@saolucas.ed $\underline{\text { u.br }}$}

\section{Hilton Marcelo de Lima Souza}

Doutor em Biotecnologia (UEA)

Professor Adjunto da

Universidade do Estado de

Mato Grosso (UNEMAT)

hilton.marcelo@unemat.br

\section{Josué Ribeiro da Silva Nunes}

Doutor em Ecologia e

Recursos Naturais (UFSCar)

Professor Adjunto da

Universidade do Estado de

Mato Grosso (UNEMAT)

josue@unemat.br
Resumo: No ensino de Biologia, o uso do método tradicional aliado a presença de conteúdos de difícil assimilação, tem sido um dos principais fatores que promovem a desmotivação dos estudantes. No entanto, o uso de jogos didáticos na escola pode contribuir para um aprendizado mais dinâmico e motivado. Este trabalho teve como objetivo avaliar a contribuição do jogo "Conhecendo os Invertebrados", como instrumento didático e motivacional para o ensino sobre a referida temática. Um protótipo do jogo foi aplicado à professores de Biologia e alunos da terceira série do ensino médio. Logo após, ambos foram entrevistados com a finalidade de avaliar a presença de determinados elementos pedagógicos no jogo, bem como sua aceitabilidade e contribuição na aprendizagem sobre a temática, respectivamente. Modificações foram realizadas no jogo, conforme indicação dos professores entrevistados e este recurso didático demonstrou ser adequado e indicado para o Ensino Médio, caracterizando-se como uma ferramenta didática e divertida para o ensino sobre Zoologia na escola.

Palavras-chave: Jogos didáticos; Ensino de zoologia; Zoologia de invertebrados.

\begin{abstract}
In the teaching of Biology, the use of the traditional method allied to the presence of content of difficult assimilation, has been one of the main factors that promote the demotivation of students. However, the use of educational games in the school can contribute to a more dynamic learning, favoring motivation to learn. The objective of this work was to evaluate the contribution of the game "knowing the Invertebrates" as a didactic and motivational instrument for teaching about this theme". A prototype of the game was applied to biology teachers and students from the third grade of high school. Shortly after, both were interviewed in order to evaluate the presence of certain pedagogical elements in the game, as well as their acceptability and contribution to learning about the theme, respectively. Modifications were made in the game, as indicated by the professors interviewed and this didactic resource proved to be adequate and indicated for high school, characterizing itself as a didactic and entertaining tool for teaching about zoology in School.
\end{abstract}

Keywords: Educational games, Zoology teaching, Invertebrate zoology. 


\section{INTRODUÇÃO}

À medida que o tempo passa, a educação sofre variações em suas metodologias e estratégias. Pelo fato dos educandos, de um modo geral, apresentarem características intrínsecas do meio em que os cercam e do tipo de informação que lhes é oferecida, tornase evidente que a docência enfrenta momentos de renovação e de reestruturação metodológica, haja vista o grande número de mudanças vividas e vigentes em diferentes épocas da sociedade (BRASIL, 1998; ROSA; ROSA, 2012).

Associado a esta realidade, o professor apresenta um papel fundamental para a materialização do fazer pedagógico em sala de aula. Para tanto, torna-se necessário o uso de táticas de aprendizagem relacionadas com a confecção e aplicabilidade de recursos didáticos. Em vários momentos nas aulas de Biologia do Ensino Médio, os alunos se deparam com termos e nomenclaturas científicas e conteúdos de difícil assimilação. Nos estudos sobre os animais, por exemplo, há muitas informações taxonômicas, anatômicas além de relações evolutivas que não são entendidas como importantes pelos alunos, fato que dificulta o aprendizado deste assunto. Então, unir um conteúdo de difícil entendimento com uma atividade mais prazerosa visando o aprendizado é algo que pode e deve ser mais aproveitado pelos professores.

Muito se tem discutido sobre o uso de metodologias diferenciadas em sala de aula e os jogos didáticos têm sido um dos principais aliados no âmbito escolar em diversos níveis de ensino, podendo contribuir na assimilação dos conteúdos, na interação entre os alunos e no desenvolvimento do raciocínio lógico (ZUANON, 2010; BRITO et al., 2012; KRASILCHIK, 2005). Nesse sentido, os jogos podem ser encarados como facilitadores no desenvolvimento de habilidades para a resolução de determinados problemas inerentes aos conteúdos que estão sendo trabalhados em sala de aula.

Logo, quando consideramos a importância de jogos lúdicos para a formação de habilidades e compreensão de muitos conteúdos da Biologia e tendo em vista que sua aplicabilidade, ainda se mostra ínfima nas escolas, há uma crescente necessidade de pesquisas que investiguem as potencialidades de atividades lúdicas, principalmente visando o aperfeiçoamento de conhecimento dos estudantes.

Diante deste contexto, o presente estudo foi realizado partindo do pressuposto que a construção de um jogo sobre a temática "Zoologia de Invertebrados" seria uma alternativa com bom aceite pelos estudantes e que auxiliaria na transmissão e aquisição de conhecimentos científicos. No entanto, faz-se necessário que o processo de construção 
de qualquer recurso didático seja validado com professores da área de Ciências Biológicas e alunos, visando o aprimoramento da qualidade e finalidades didáticas do produto.

Diante deste contexto, o objetivo deste trabalho foi apresentar uma proposta de jogo didático em forma de tabuleiro denominado "Conhecendo os Invertebrados", visando complementar a ação do professor em sala de aula e auxiliando na abordagem de conteúdos sobre Zoologia dos invertebrados, que muitas vezes são extensos e de difícil assimilação. Além da apresentação da proposta do jogo, também se objetivou realizar uma avaliação do recurso didático proposto, tanto com professores quanto com alunos do Ensino Médio, para desenvolvimento de melhorias e validação deste jogo como um produto pedagógico de aprendizado e motivação, contribuindo assim para o ensino de Biologia.

\section{REFERENCIAL TEÓRICO}

O grande desafio do professor de Biologia é tornar o ensino agradável, prazeroso e instigante, sendo capaz de desenvolver no discente o "Saber Científico" sem que o educando se torne apenas um acumulador de conhecimento. Embora estejamos em um tempo em que o uso de tecnologia na educação tem aumentado, outros recursos didáticos, considerados simples por serem confeccionados com materiais de baixo custo, precisam ser retomados na escola, pois as atividades didáticas e lúdicas estimulam o trabalho em grupo e a interação, aspectos necessários em uma sociedade atualmente corrompida pelo excesso de acesso às tecnologias da informação que tem acentuado o individualismo em nossos jovens (CARMO; SCHIMIN, 2008; MALACARNE; STRIEDER, 2009; BRITO et al., 2012).

Os jogos didáticos são recursos psicopedagógicos de grande importância na aprendizagem, devendo o professor proporcionar situações e condições favoráveis para que uma nova informação seja assimilada e associada a conhecimentos prévios dos alunos, favorecendo a possibilidade de aprender conteúdos disciplinares através de metodologias mais dinâmicas em sala de aula (COLL et al., 2003; CANDIDO e FERREIRA; 2012). Através do jogo didático, podem-se atingir diversos objetivos psicopedagógicos relacionados à cognição, socialização, motivação e criatividade, possibilitando uma aprendizagem significativa (MIRANDA, 2001).

Ainda hoje, os jogos são subutilizados como instrumentos didáticos e muitos professores desconhecem seus reais benefícios. Em décadas atrás, eram considerados 
como pouco úteis para a aprendizagem e dessa forma, a utilização do jogo como meio educativo demorou a ser aceita e incorporada no ambiente educacional, embora tal importância tenha sido mencionada como proposta de inovação dos currículos escolares desde os Parâmetros Curriculares Nacionais (BRASIL, 2006; CARMO; SCHIMIN, 2008). Em meio a várias modalidades didáticas existentes, o uso de jogos, aulas práticas e projetos são relatados por Krasilchik (2005) como os mais apropriados para proporcionar uma alfabetização científica.

Segundo Grando (1995), entre os benefícios da utilização de jogos no contexto educacional, pode-se destacar a introdução e desenvolvimento de conceitos de difícil compreensão; participação ativa do aluno na construção do seu próprio conhecimento; socialização e a conscientização do trabalho em equipe, além de motivar os alunos a participarem da aula.

O ensino de Ciências e Biologia têm sido estigmatizados por muitos alunos como difícil, pela existência de diversas nomenclaturas científicas, mas que de certa forma, se tornam necessárias para o entendimento quanto à importância de cada grupo de seres vivos, sua relação com o meio ambiente e o ser humano. Associado a este aspecto, destaca-se como agravante o uso exclusivo do livro didático para lecionar os assuntos, carência de recursos pedagógicos alternativos, aulas tendo a exposição oral como único recurso, além do tempo reduzido do professor para planejar e executar suas atividades acadêmicas em sala de aula (TIDON; LEWONTIN 2004).

Entre outros fatores, torna-se generalizada a inexistência de certas condições materiais e a falta de coleções biológicas nas escolas, não permitindo ao professor a realização do trabalho docente sem ter que se apropriar continuamente da tradicional aula expositiva conteudista (SEIFFERT-SANTOS; FACHÍN-TERÁN, 2011).

Mergulhado neste contexto, também se encontra o ensino sobre a Zoologia, que compreende o estudo dos animais. Ademais, na maioria das vezes, acrescenta-se a falta de identificação com os animais utilizados como exemplos no ensino e até a ausência dos grupos animais locais (SEIFFERT-SANTOS; FACHÍN-TERÁN, 2009). Esta realidade também se estende aos estudos dos animais invertebrados, um dos maiores grupos de organismos do mundo e tem importante relação e envolvimento no cotidiano dos estudantes.

Os invertebrados compõem mais de $99 \%$ das espécies de animais, sendo fundamental compreender e aprender sobre suas características para aplicar esses 
conceitos e utilizá-los a favor da sociedade, pois tais organismos interagem ecologicamente, economicamente, socialmente. Além disso, torna-se essencial incluí-los no ensino escolar pelo fato dos invertebrados estarem presentes no cotidiano dos alunos, uma vez que, dentre outros motivos, certos organismos são causadores ou vetores de doenças que podem nos atingir (BRUSCA; BRUSCA 2007).

A literatura na área de ensino de Biologia e Zoologia tem demonstrado que o uso de jogos didáticos e lúdicos, tais como jogo da memória, baralhos, tabuleiros entre outros, embora simples, tem demonstrado que são importantes instrumentos no aprendizado (CAMPOS; BORTOLO; FELICIO, 2003; CANDIDO; FERREIRA 2012; SILVA; MASSAROLLI; BUTNARIU, 2017). Em todos estes trabalhos, os autores relatam a boa aceitabilidade e a importância do dinamismo presente em jogos, tornando o raciocínio mais rápido, estímulo a uma competitividade saudável, vinculada a vontade de aprender sobre o assunto, gerando uma aprendizagem prazerosa.

\section{Metodologia}

\subsection{O JOGO "CONHECENDO OS INVERTEBRADOS"}

O jogo foi desenvolvido como requisito avaliativo parcial do Programa de Mestrado Profissional em Ensino de Biologia em Rede Nacional (PROFBIO) da Universidade do Estado de Mato Grosso (UNEMAT), campus de Tangará da Serra. Foi construído levando em consideração o disposto nos Parâmetros Curriculares Nacionais (PCN), na Base Nacional Comum Curricular (BNCC) no que diz respeito ao ensino de Zoologia dos Invertebrados e embasado em coleções didáticas atuais e utilizadas pelos professores do Ensino Médio (AMABIS; MARTHO 2016).

"Conhecendo os Invertebrados" aborda as questões morfológicas, fisiológicas, ecológicas e evolutivas dos oito principais filos de animais invertebrados: Porífera, Cnidária, Platyhelminthe, Nemathelminthe, Mollusca, Annelida, Arthropoda e Echinodermata. É um recurso que propõe a assimilação do conteúdo supracitado de forma interativa, desafiadora e divertida e propõe uma maneira diferente para se abordar o referido conteúdo, interligando os filos animais ao mesmo tempo em que associa a evolução do grupo.

O jogo é composto de um tabuleiro, 165 cartas, 10 pinos didáticos, um dado, um manual de regras e respostas e aceita entre 4 e 10 participantes, cujo objetivo é chegar primeiro ao final do tabuleiro após passar por todos os desafios propostos. Para estimular 
ainda mais o estudante, o jogo foi elaborado levando em consideração o estímulo visual, a competitividade, o desafio e a diversão.

\subsection{ESTRUTURA E APRESENTAÇÃO DO JOGO}

O tabuleiro do jogo apresenta 38 casas (Figura 1A). O tamanho do tabuleiro e das casas foi pensado com base nos pinos produzidos para os jogadores que foram produzidos artesanalmente em massa de biscuit com as formas de animais representantes dos filos abordados no jogo (Figura 1B).

Entre as casas distribuídas pelo tabuleiro existem:

- Casas informativas, cuja intenção é fazer com que o jogador faça a leitura de uma carta que contém informações relacionadas ao Filo identificado na casa;

- Casas de Ação, identificadas como "Sorte ou Azar" que permitem que o jogador leia uma situação em que os animais dos filos do jogo estão causando prejuízo ou benefício, ou ainda, situações que expressam o comportamento dos animais;

- Casas de Ação, identificadas com um sinal de interrogação (?) que permitem que o jogador retire uma das cartas "Teste seus Conhecimentos" e leia uma pergunta sobre um dos filos dos animais invertebrados, podendo avançar ou retroceder no tabuleiro caso tenha sucesso ou fracasso na sua resposta (Figura 1A).

As cartas do jogo são divididas em dois grupos principais: cartas de ação e cartas informativas, com funções distintas:

- As cartas de ação "Teste seus conhecimentos", foram elaboradas com perguntas retiradas de sites de domínio público onde os conhecimentos do jogador são colocados à prova. Foram confeccionadas 30 cartas, cada uma delas com uma pergunta diferente sobre os 8 filos animais abordados no jogo (Figura 1C);

- As cartas de ação "Sorte ou Azar", trazem situações inusitadas elaboradas para criar uma interação do jogador com espécimes dos filos abordados pelo jogo. A linguagem destas cartas é informal e as situações da carta podem fazer o jogador avançar ou retroceder no jogo (Figura 1D);

- As cartas de informação estão distribuídas de acordo com os filos animais que são abordados no jogo. Foram elaboradas 110 cartas que trazem informações sobre a ecologia, distribuição, morfologia, fisiologia, evolução ou ainda sobre curiosidades dos animais (Figura 1E). 
Figura 1 - A: Tabuleiro do jogo (120cm x 90cm); B: Pinos produzidos em massa de biscuit; C: Carta teste seus conhecimentos; D: Carta Sorte ou Azar e E: Carta de informação
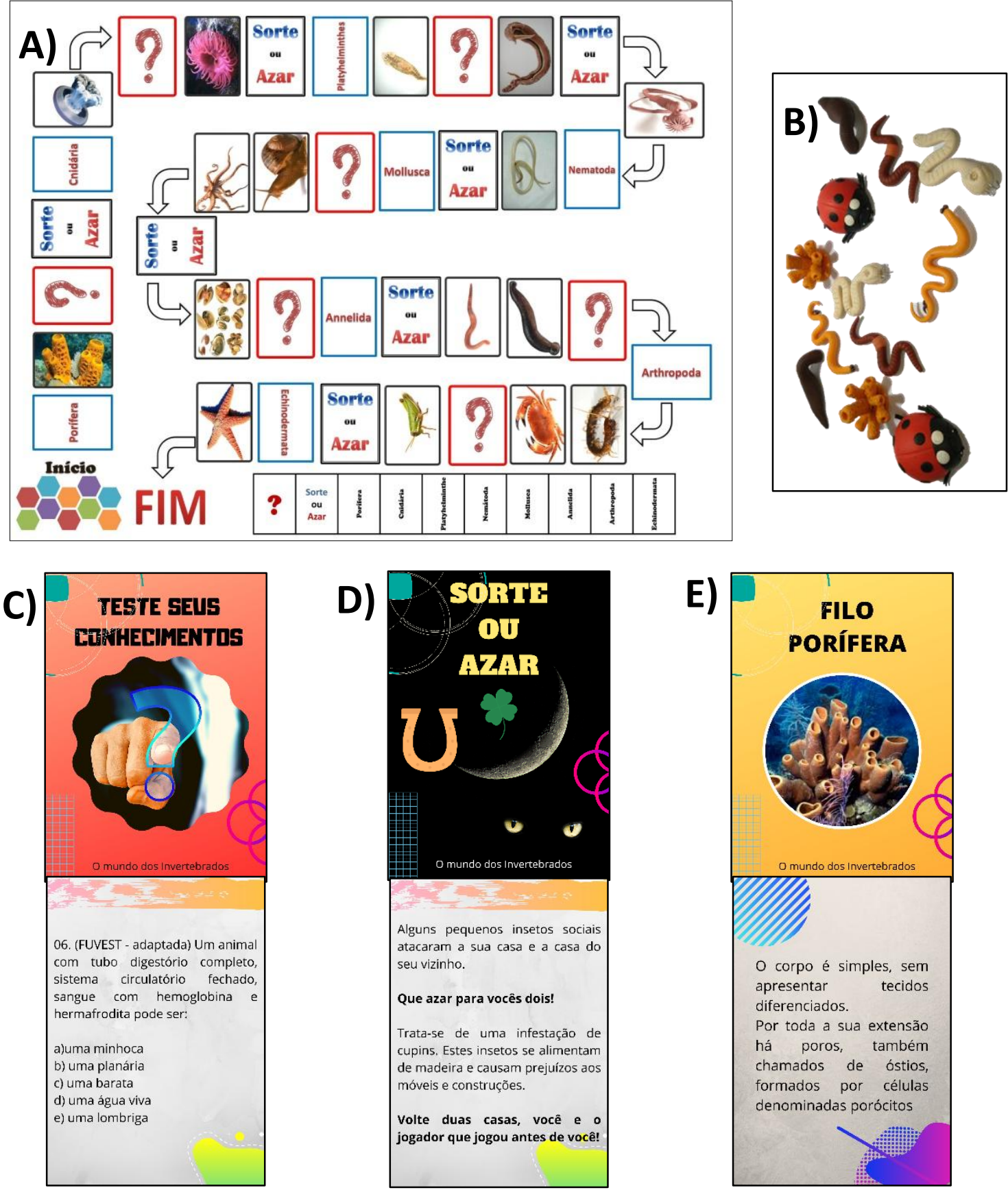

Fonte: os autores

O jogo tem início após a escolha dos animais (pinos) para representarem os jogadores e disputa de posições através do lançamento de dados. Cada um dos jogadores respeitando a ordem obtida no início do jogo deve fazer o lançamento do dado e percorrer o número de casas indicada pela face superior do dado.

Ao cair em uma casa de informação o jogador deve retirar uma carta de informação correspondente ao filo indicado na casa, ler as informações em voz alta. Ao cair nas casas de ação, (teste seus conhecimentos e sorte ou azar) o jogador deve retirar 
uma carta correspondente e efetuar a leitura da carta em voz alta e cumprir o que designa a carta. Se for uma carta de sorte ou azar, ou se for uma pergunta, o jogador pode avançar ou retroceder casas dependendo da informação descrita na carta.

As regras, os procedimentos e as ações do jogo podem ser consultadas por meio de um manual com orientações, explicando todas ações que devem ser tomadas em cada uma das situações propostas no jogo. Junto a este manuscrito, uma versão simplificada e reduzida do jogo está disponível como Material Suplementar (Anexo).

\subsection{APLICAÇÃO E AVALIAÇÃO: CONTRIBUIÇÃO DOS PROFESSORES}

O protótipo do jogo foi aplicado a professores da área de Ciências biológicas e logo após, os mesmos foram convidados a responder um questionário semiestruturado contendo cinco questões, com o objetivo de obter informações que pudessem agregar maior caráter pedagógico ao jogo. Além de registrar o perfil do entrevistado, as questões referiam-se ao nível de aceitabilidade do jogo, contribuição para aprendizagem, nível de ensino que o jogo torna-se adequado, bem como uma avaliação da presença de determinados componentes pedagógicos importantes, tais como: 'criou situações de aprendizagem' (A), ‘memorização de conceitos' (B), ‘aquisição de novos conhecimentos' (C), 'proporciona mais que conceitos teóricos' (D), 'interação entre os participantes' (E), 'diversão' (F) que aferiu o nível de animação gerado pela atividade; 'estrutura do tabuleiro' (G), que qualificou o design, a organização e as imagens dispostas no tabuleiro, e por último o item 'auxilia no aprendizado em grupo' $(\mathrm{H})$.

Os dados coletados foram analisados por estatística descritiva e análise quantitativa de categorias, adaptada de Bardin (2011), para as respostas obtidas nas perguntas abertas do questionário. O resultado dessas análises e as sugestões oferecidas pelos professores participantes forneceram embasamento para alterações no protótipo do jogo.

\subsection{APliCaÇão e aVAliaÇão COM alunOS do ENSINO MÉdio}

O jogo “Conhecendo os Invertebrados” foi aplicado ente março e abril de 2019, em duas turmas de terceiro ano do Ensino médio, em uma escola da rede estadual de educação no município de Ji-Paraná, Rondônia. No total, participaram da atividade 60 alunos, com idades entre 15 e 18 anos. As turmas escolhidas já haviam estudado o conteúdo de Zoologia de invertebrados durante o terceiro bimestre do ano anterior. 
Supõe-se então que, os conteúdos abordados pelo jogo eram de conhecimento prévio dos estudantes.

Para obter a avaliação dos estudantes sobre o jogo, cada estudante recebeu um questionário de opinião. Para a formulação das perguntas optou-se por utilizar a metodologia ARCS de avaliação de jogos, propostas por Keller (2009). ARCS é um acrônimo que define 4 categorias de estratégias relevantes para a motivação dos alunos na aprendizagem: Atenção, Relevância, Confiança e Satisfação (Attention, Relevance, Confidence, and Satisfaction).

A metodologia ARCS leva em consideração a motivação e a interação do jogador com o ambiente de aprendizagem e é derivado da teoria de que expectativa (probabilidade de um indivíduo obter sucesso) e valor (satisfação de necessidades pessoais ou motivos) são determinantes para o esforço empregado em uma ação.

Para cada categoria estratégica $(\mathbf{A}=$ Attention, $\boldsymbol{R}=$ Relevance, $\boldsymbol{C}=$ Confidence, $e$ $\boldsymbol{S}=$ Satisfaction) foi elaborado de 3 a 4 itens a serem avaliados pelos alunos, considerando uma escala de 1 a 5, totalizando 14 questionamentos. Na categoria "A", avalia-se a capacidade que o jogo tem de capturar a atenção do estudante e o nível de atenção do aluno durante o processo; em " $\mathrm{R}$ " investiga-se a capacidade do aluno perceber a conexão do conteúdo com seus objetivos e os associarem com as novas informações; "C" relacionada à possibilidade do estudante criar expectativas positivas, através de experiências de sucesso decorrentes do seu próprio esforço; "S" avalia o quanto foi satisfatório para o jogador em relação a sua experiência, incluindo nívelamento de desafios do jogo, diversão mútua entre participantes, aceitação e nível de indicação para aprendizagem quando em comparação com outros métodos usados no ensino sobre o assunto (KELLER, 2009).

Para conhecer como os alunos se autoavaliam quanto ao conhecimento sobre Zoologia de Invertebrados (Filos: Anelídeo, Platelminto, Artrópode, Molusco), antes e após o jogo, foi inserido no questionário mais uma pesquisa de opinião considerando a mesma escala de 1 a 5, utilizada nas questões anteriores. As questões referiam-se a: "Lembrar o que é", que faz referência a lembrança do conteúdo estudado sobre invertebrados e associa sua lembrança aos representantes do grupo; "Conhecer as funções biológicas" que se refere ao conhecimento acerca da fisiologia, morfologia e ecologia dos grupos, e por último, "Diferenciar de outros grupos", que infere a capacidade de reconhecer as características evolutivas e morfológicas dos grupos como uma forma de 
diferenciá-los. Para que esses dados pudessem ser comparados, os itens foram agrupados por Filo e dispostos em 'antes' e 'depois'.

Todos os resultados obtidos foram avaliados em cada categoria pela média das respostas, sendo apresentados em gráficos elaborados por meio do Programa Excel@. Por fim, para que os estudantes possam contribuir para avaliação e auxiliar na validação deste recurso didático, duas questões discursivas também foram acrescentadas, sendo as respostas analisadas qualitativamente.

Essa pesquisa segue os princípios éticos sobre pesquisas realizadas com seres humanos, tendo aprovação pelo Comitê de Ética em Pesquisa (CEP). Todos entrevistados aceitaram participar voluntariamente, sendo recolhido os Termos de Assentimento e Termo de Livre Consentimento Esclarecido devidamente assinados.

\section{Resultados}

$\mathrm{O}$ jogo apresentou características atrativas aos estudantes e professores participantes. Ao verem o tabuleiro do jogo com diversas imagens e um tamanho muito superior do que os tabuleiros tradicionais $(120 \mathrm{~cm} \times 90 \mathrm{~cm})$, os jogadores (alunos ou professores) demonstraram surpresa e animação. Quando os pinos do jogo foram apresentados (réplicas de animais dos respectivos filos), houve certa euforia para escolha dos animais preferidos.

Durante o jogo, notou-se que os participantes se sentiam animados, entretanto quando este passava de uma hora por rodada, foi possível observar um certo distanciamento da proposta. O número de casas do tabuleiro, bem como o número de cartas pode ser reduzido a escolha do professor mediador da atividade, objetivando a redução do tempo de jogo para que a animação seja mantida até o fim. Durante este trabalho, as rodadas levaram de cinquenta minutos até uma hora e vinte minutos.

O jogo aceita adaptações que podem variar desde o número de cartas até o número de jogadores, variando de acordo com o tamanho da turma e número de alunos envolvidos na atividade. Quando utilizado antes da apresentação do conteúdo aos estudantes, o jogo pode ser mais curto, com menos cartas e menos casas no tabuleiro afim de que este suscite curiosidade no aluno. Caso a atividade seja proposta após a explanação do conteúdo, sugere-se que o jogo seja utilizado com todas as cartas e até mesmo com outras que podem ser criadas pelo professor mediador, pois o jogo se tornaria uma forma dinâmica de avaliar a compreensão dos estudantes sobre o assunto. 
O grupo de professores participantes deste estudo foi composto por $63,3 \%$ de mulheres e 36,7\% homens, tendo a faixa etária predominante de 31 a 40 anos, perfazendo 43,3\% do total, entretanto, é possível observar a participação de professores com idades superiores a 51 anos. Também, faz-se pertinente, citar que os professores buscam atualizar-se quando o assunto é a docência, pois 3,3\% dos participantes possuem apenas a graduação e o restante possuem no mínimo uma pós-graduação lato sensu, mestrado ou doutorado.

A atuação destes docentes foi distribuída predominantemente entre o Ensino Fundamental e Médio, com mais de 66\% dos participantes lecionando no Ensino Médio. Quanto a aceitabilidade e importância do jogo para o aprendizado, cerca de $80 \%$ dos professores consideraram como sendo um ótimo recurso didático e $20 \%$ o consideram bom. Além disso, todos os professores consideraram que o jogo pode contribuir para aprendizagem dos alunos. Sobre a aplicabilidade do jogo a determinados níveis de ensino, $80 \%$ dos entrevistados mencionaram que o mesmo se torna mais adequado para uso no Ensino Médio tendo em vista o conteúdo abordado e a forma como ele está disposto no jogo (Figura 2A).

$\mathrm{Na}$ avaliação dos componentes pedagógicos, os professores julgaram cada um dos itens com os conceitos 'ótimo, bom, regular ou fraco'. O item 'diversão' (F) obteve 93,3\% de respostas com conceito ótimo. Os itens 'interação entre os participantes' (E), 'aquisição de novos conhecimentos' (C), 'proporciona mais que conceitos teóricos (D)' e 'auxilia no aprendizado em grupo' $(\mathrm{H})$ obtiveram respostas entre 80 a $86 \%$ com conceito ótimo.

Por conseguinte, o item que obteve a menor taxa de respostas 'ótimo', revelou que eram necessárias algumas alterações na estrutura do jogo, haja vista que 50\% dos professores assinalarem o conceito 'bom' para o item 'estrutura do tabuleiro' (Figura 2B). Todos estes aspectos elencados possuíram boa avaliação pelos professores. Em consonância com os dados obtidos, e levando em consideração as respostas e sugestões dos participantes da pesquisa, alterações no layout do tabuleiro do jogo foram realizadas e adequações nas cartas foram feitas. 
Figura 2 - A. Respostas da questão "Você considera esse jogo adequado para qual nível de ensino?”.
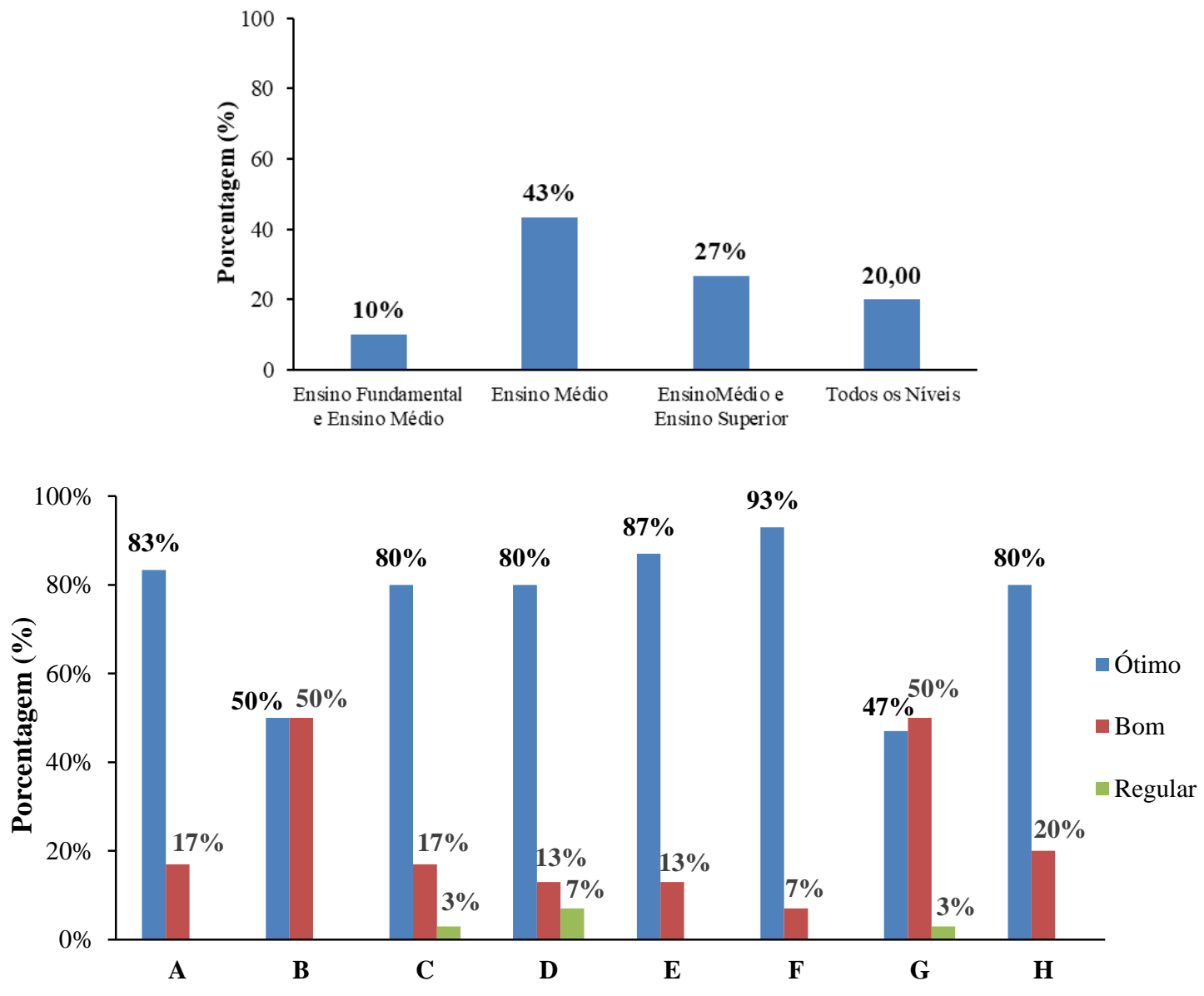

Fonte: os autores

O resultado da pesquisa de opinião com alunos do Ensino Médio sobre o jogo "Conhecendo os Invertebrados" demonstrou que houve ótima avaliação deste recurso didático em todos os quesitos aplicados. Todas as categorias de avaliação "Atenção", "Relevância", "Confiança", "Relevância" alcançaram, entre uma escala de 1.0 a 5.0, valores médios acima de 4.38 (Figura 3). Estes resultados sugerem que há uma evidente aceitabilidade a proposta do jogo pelos estudantes, sendo os mesmos atraídos tanto pelos aspectos estruturais, quanto àqueles relacionados à relação interpessoal, emocional e cognitivo, aspectos que favorecem uma aprendizagem significativa. 
Figura 3 - Resultados das respostas dos estudantes as respectivas categorias estratégicas de Keller (2009):

(A) Categoria Atenção; (B) Categoria relevância; (C) Categoria confiança e (D) Categoria satisfação.
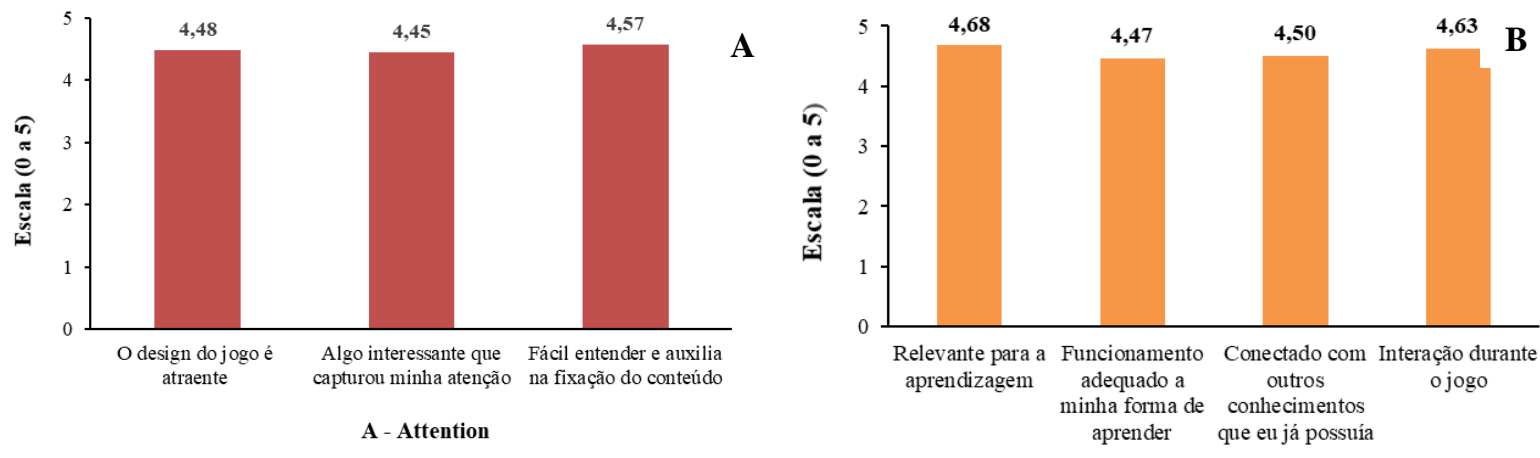

R - Relevance
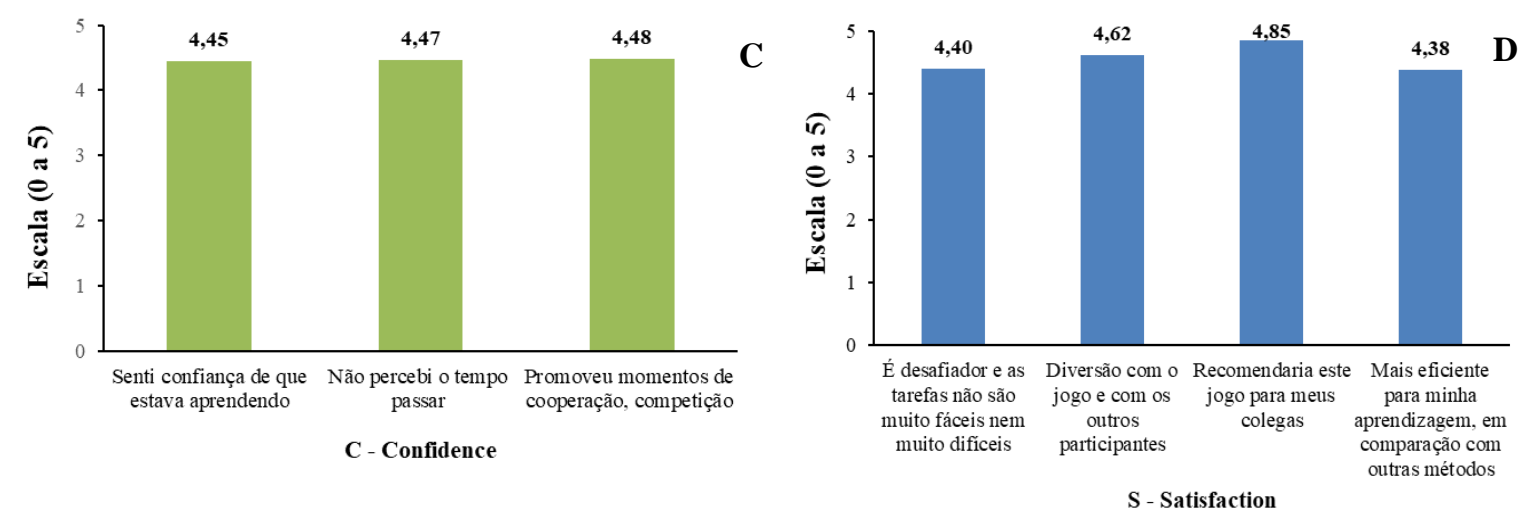

Fonte: os autores

Quanto ao conhecimento dos alunos sobre Zoologia de Invertebrados "antes" e “depois" da aplicação do jogo, observa-se que mesmo admitindo que já possuíssem conhecimento sobre os assuntos, os estudantes atribuíram conceitos baixos sobre o conhecimento que prévio que eles possuíam. Em contrapartida, após o jogo, os estudantes atribuíram conceitos superiores para todos os itens avaliados (Figura 4).

Diante dos dados expostos nos gráficos, é relevante destacar que ao compararmos o antes e depois de cada um dos itens, nota-se que os conceitos assinalados para o grau de conhecimento sobre os filos 'depois' do jogo sobrepõem-se aos conhecimentos prévios. No item 'conhecer as funções biológicas', dos gráficos da Figura 4, nota-se que 'antes' os estudantes assinalaram conceitos que atingiram médias não superiores a 2,35 enquanto os resultados para 'depois' do jogo atingiram médias de 4,77, perfazendo resultados $100 \%$ superiores quando comparados antes e depois. Os outros itens da avaliação 'antes' e 'depois', possuem médias semelhantes, onde os resultados para 'depois' do jogo são entre 80 e 100\% maiores em relação aos conhecimentos 'antes' do jogo. Assim, os resultados apresentados evidenciam e confirmam que o uso do lúdico no 
ensino tem sido uma ótima alternativa, conforme vem sendo relatado na literatura (CAMPOS; BORTOLOTO; FELICIO, 2003; LIMA, 2015).

Figura 4 - Resultados das respostas à percepção de conhecimento antes e depois do jogo sobre os filos:

(A) Filo Platyhelminthe; (B) Filo Molusca; (C) Filo Annelida e (D) Filo Arthropoda
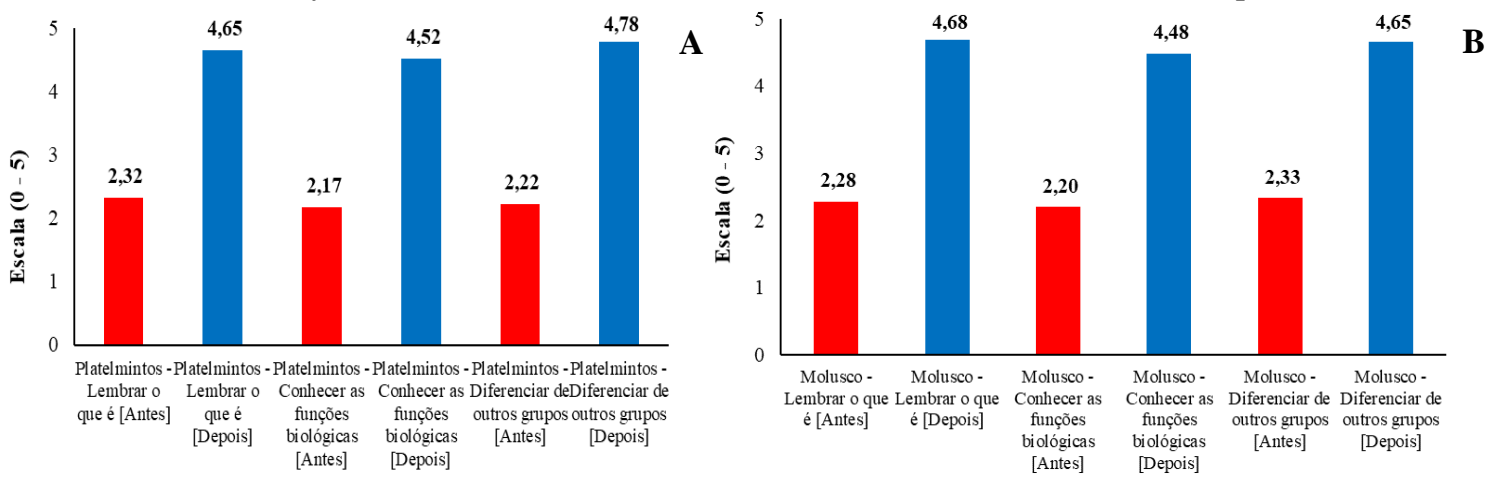

$\mathbf{C}$
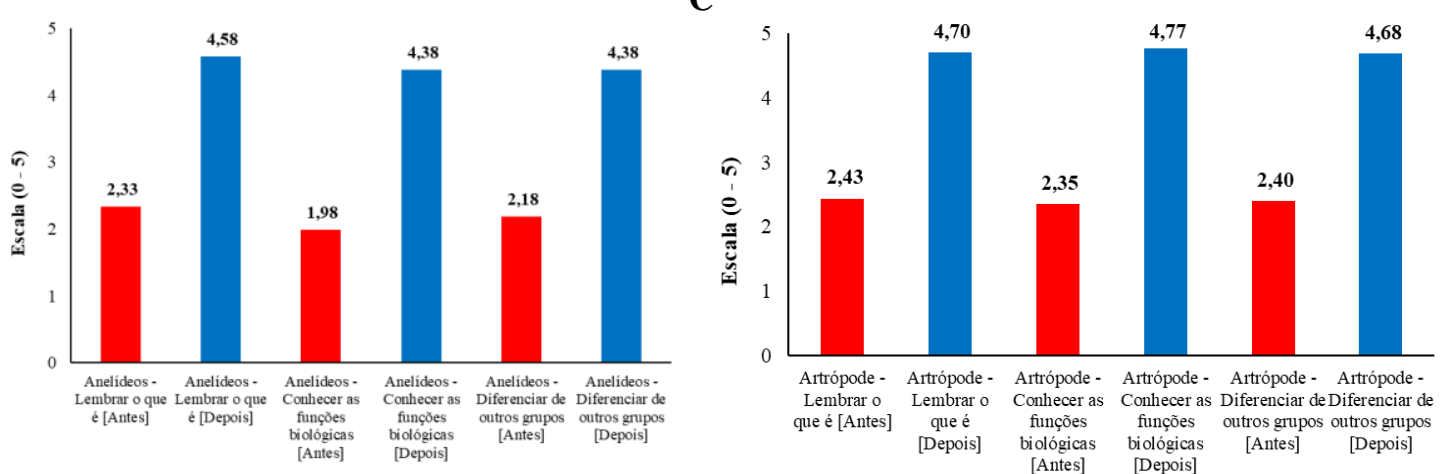

Fonte: os autores

Através das respostas dos alunos quanto questionados sobre os pontos fortes do jogo, foi possível a elaboração qualitativa de cinco categorias de análises (adaptada de Bardin, 2011): i) Estrutura/Layout do jogo, que agrupou as respostas relacionadas às cartas, aos pinos, ao tabuleiro ou ainda à organização do jogo; ii) Aprendizado, onde os estudantes citaram sobre assimilação do conteúdo, sobre aprendizado proporcionado pelo jogo ou ainda sobre a associação com o cotidiano; iii) Conteúdo, que organizou as respostas que tratavam de como o conteúdo foi exposto, de como os assuntos foram abordados ou ainda afirmações positivas sobre os temas utilizados; iv) Diversão, que agrupou respostas associadas as expressões de animação, lazer, alegria e brincadeira em relação ao jogo; v) Interação, compreendeu as respostas que fizeram associação a maneira que os estudantes participaram do jogo ou ainda como estes interagiram com o jogo e entre si.

Quando instigados a citar os pontos fortes do jogo, os estudantes mencionaram em sua maioria que a estrutura do jogo e seu layout (28\%), é um ponto forte, bem como 
o aprendizado proporcionado pelo jogo (27\%). Em seguida os pontos 'conteúdo' e 'diversão' se mostram evidentes, demonstrando que mesmo abordando conteúdos de difícil assimilação o jogo conseguiu proporcionar diversão aos participantes (Figura 5).

Figura 5 - Resultado da categorização dos pontos fortes citados pelos alunos participantes

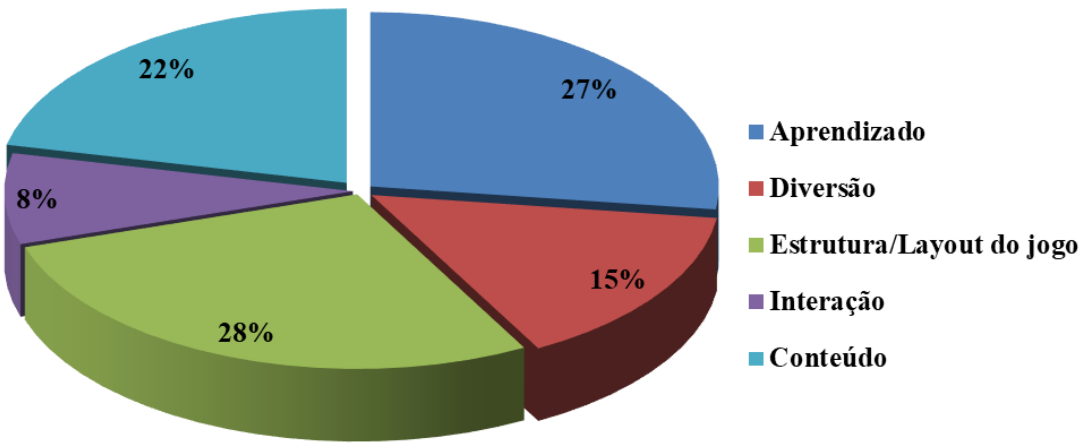

Fonte: os autores

A seguir, destacam-se algumas falas dos alunos que demonstram os pontos fortes que os mesmos encontraram:

A1: "O conteúdo ficou gostoso de aprender".

A2: "As cartas de azar são engraçadas e ajudam a associar o conteúdo com a prática".

A3: "Faz o aluno participar da aula"

A4: “As cartas do jogo trazem muitas informações legais, o jogo é divertido e o conteúdo ficou gostoso de aprender".

A5: "O jogo apresenta uma forma prática de entender a ação desses invertebrados na natureza e cotidiano com o 'sorte e azar', as questões podem ser reutilizadas como forma de estudo e gera interesse em conhecer e saber diferenciar cada grupo".

A6: "Os pinos, a compreensão do conteúdo e a interação com os colegas".

Em geral, os professores que avaliaram o jogo reconhecem a presença de importantes componentes pedagógicos, principalmente relacionados a diversão e a interação entre os participantes. Tais aspectos vêm sendo relatados na literatura como os principais em propostas didáticas de ensino, corroborando com a literatura. A troca de informações e interação entre os participantes, a ludicidade e diversão associada ao desenvolvimento de raciocínio tem sidos os pilares dos jogos didáticos eficazes e que favorecem aquisição de conhecimentos de forma efetiva (MIRANDA, 2001; ANTUNES, 2003; MENDES; BRANDÃO; SANTOS, 2011). 
Os estudantes envolvidos nesta pesquisa demonstraram ótima aceitabilidade a proposta do jogo e atribuíram um melhor desempenho acadêmico, maior assimilação e aprendizado do conteúdo de Invertebrados, demonstrando o potencial do recurso didático apresentado. Diversos trabalhos na literatura têm reforçado que os estudantes consideram os jogos como ferramentas importantes para promover o aprendizado, devido a seu caráter desafiador, de diversão e prazer associado (MACEDO, 2003; SILVA; MASSAROLLI; BUTNARIU，2017; CAMPOS; BORTOLOTO; FELICIO，2003; ZUANON, 2010; FIALHO, 2008), fatos que corroboram com os resultados obtidos neste trabalho.

Conforme os resultados apresentados, pode-se afirmar que a estrutura do tabuleiro, suas peças e pinos também foram um fator influenciador no sucesso de aceitabilidade e eficácia na aprendizagem, demonstrando que a criatividade docente para construção de recursos didáticos tem importante papel para atrair a atenção dos alunos para os conteúdos abordados. Por fim, os resultados deste trabalho reforçam que, toda e qualquer estratégia didática que foge do ensino tradicional, principalmente vinculada a interatividade e diversão, tende a ser bem recebida pelo estudante, aspecto este que traz a reflexão a necessidade docente de agregar diversas estratégias didáticas em sala de aula para garantia plena da formação do cidadão em nossas escolas.

\section{CONSIDERAÇÃo FINAL}

A criação do jogo "Conhecendo os Invertebrados" mostrou-se pertinente como proposta para o ensino de Biologia. Os professores participantes deste estudo reconhecem a presença de importantes componente pedagógicas na proposta do jogo e que facilitam a aprendizagem. Durante e após a aplicação do jogo, os estudantes demonstram-se satisfeitos e com maior compreensão sobre a temática "Invertebrados". A análise dos resultados da avaliação do jogo demonstra a eficácia deste recurso didático,

principalmente pelo caráter motivador, podendo proporcionar diversão aliada a construção de conhecimentos, principalmente pela forma com que o conteúdo de Zoologia dos Invertebrados foi apresentado. Pelo exposto, confirma-se que o referido jogo pode contribuir na prática pedagógica dos professores de Biologia.

\section{REFERÊNCIAS}

AMABIS, José Mariano; MARTHO, Gilberto Rodrigues. Biologia moderna, 1. ed. São Paulo: Moderna, 2016. 
ANTUNES, Celso. O jogo e a educação infantil: Falar e dizer, olhar e ver, escutar e ouvir. 4. ed. Petrópolis: Vozes, 2003.

BARDIN, Lawrence. Análise de conteúdo. São Paulo: Edições 70. 2001.

BRASIL. Ministério da Educação e do Desporto. Secretaria de Educação Fundamental. Parâmetros curriculares nacionais terceiro e quarto ciclos do ensino fundamental: introdução aos parâmetros curriculares nacionais. Brasília, DF: MEC/SEF, 1998.

BRASIL. Secretaria de Educação Fundamental. Parâmetros curriculares nacionais: Ciências Naturais. Brasília: MEC/SEF, 2006.

BRITO, Lya Cristina da Costa et al. Avaliação de um minicurso sobre o uso de jogos no ensino. Revista Brasileira de Pós-graduação (supl 2), Brasília, v. 8, n.2, p. 589-615, 2012. Disponível em: http://ojs.rbpg.capes.gov.br/index.php/rbpg/article/view/257/246. Acesso em 15 out. 2018.

BRUSCA, Richard; BRUSCA, Gary. J. Invertebrados. 2. ed. Rio de Janeiro: Guanabara-Koogan, 2007.

CAMPOS, Luciana Maria Lunardi; BORTOLOTO, Tânia Mara; FELICIO, Ana Karina. A produção de jogos didáticos para o ensino de ciências e biologia: uma proposta para favorecer a aprendizagem. Cadernos dos Núcleos de Ensino, São Paulo, p. 35-48, 2003. Disponível em: http://www.unesp.br/prograd/PDFNE2002/aproducaodejogos.pdf. Acesso em: 16 maio 2018.

CANDIDO, Camila; FERREIRA, Jaqueline de Freitas. Desenvolvimento de material didático na forma de um jogo para trabalhar com zoologia dos invertebrados em sala de aula. Cadernos da Pedagogia. São Carlos, v. 6 n. 11, p. 22-33, 2012. Disponível em: http://www.cadernosdapedagogia.ufscar.br/index.php/cp/article/viewFile/431/186. Acesso em: 02 abr. 2018.

CARMO, Solange do; SCHIMIN, Elaine Strack. O ensino da biologia através da experimentação. 2008. Disponível em:

http://www.diaadiaeducacao.pr.gov.br/portals/pde/arquivos/1085-4.pdf. Acesso em: 21 set. 2018, 21:35:00

CARNEIRO, Ana Paula Netto. A Evolução Biológica aos olhos de professores não licenciados. 2004. 137 f. Florianópolis: Dissertação (Mestrado em Educação Científica e Tecnológica) - Centro de Ciências Físicas e Matemáticas, Universidade Federal de Santa Catarina, Florianópolis, 2004. Disponível em: https://repositorio.ufsc.br/bitstream/handle/123456789/87246/210787.pdf?sequence=1. Acesso em: 20 dez. 2018.

COLL, César et al. Psicologia da aprendizagem no Ensino Médio. Rio de Janeiro: Artmed, 2003.

FIALHO, Neusa Nogueira. Os jogos pedagógicos como ferramentas de ensino. In: Congresso Nacional de Educação (EDUCERE), 8, 2008, Curitiba. Anais [...]. Curitiba: PUCPR, 2008, p. 12298-12306. Disponível em: https://educere.bruc.com.br/arquivo/pdf2008/293_114.pdf. Acesso em: 20 dez. 2018. 
GRANDO, Regina Celia. O jogo [e] suas possibilidades metodológicas no processo ensino-aprendizagem da matemática. 1995. 175f. Campinas: Dissertação (Mestrado em Educação) - Universidade Estadual de Campinas, Faculdade de Educação, Campinas, 1995. Disponível em:

http://www.repositorio.unicamp.br/handle/REPOSIP/253786. Acesso em: 19 jul. 2018.

KELLER, John M. Motivational Design for Learning and Performance: The ARCS Model Approach. Springer, 2009.

KRASILCHIK, Myrian. Prática de Ensino de Biologia. São Paulo: Editora da Universidade de São Paulo, 2005.

LIMA, Eliane Cristina Campos. Concepção, construção e aplicação de atividades lúdicas por licenciandos da área de ensino de ciências. 2015. 156 f. São Paulo: Dissertação (Mestrado em Ensino e História das Ciências e Matemática) Universidade Federal do ABC, São Paulo, 2015. Disponível em:

http://biblioteca.ufabc.edu.br/index.php?codigo_sophia=95908. Acesso em $06 \mathrm{fev}$. 2018.

MACEDO, Lino de; PETTY, Ana Lúcia Sícolli; PASSOS, Norimar Christe. Os jogos e o lúdico na aprendizagem escolar. Porto Alegre: Artmed. 2003.

MALACARNE, Vilmar; STRIEDER, Dulce Maria. O desvelar da ciência nos anos iniciais do ensino fundamental: um olhar pelo viés da experimentação. Vivências: Revista Eletrônica de Extensão da URI, v. 5, n. 7, p. 75-85, 2009. Disponível em: http://www.educadores.diaadia.pr.gov.br/arquivos/File/2010/artigos_teses/2011/ciencias 102desvelar_ciencia_anos_iniciais.pdf, Acesso em: 20 jun. 2018.

MENDES, Mariana Bonfim Pinto; BRANDÃO, Rafael Antonio; SANTOS, Andréia de Queiroz. Palavras integradoras: uma abordagem didática para o ensino de Botânica na escola. Revista Intercâmbio dos Congressos Internacionais de Humanidades, Brasília, out. 2011. Trabalho apresentado no XIV Congresso Internacional de Humanidades, 2011, [Brasília, DF]. Disponível em: https://2014.revistaintercambio.net.br/24h/pessoa/temp/anexo/1003/1315/2126.pdf. Acesso em: 12 de out. de 2018.

MIRANDA, Simão. No Fascínio do jogo, a alegria de aprender. Ciência Hoje, São Paulo, v. 28 n. 168, p. 64-66, 2001.

ROSA, Cleici Werner da; ROSA, Alvaro Becker da. O ensino de ciências (Física) no Brasil: da história às novas orientações educacionais. Revista Ibero-americana de Educação, Madri, v. 58, n. 2, p. 1-24, 2012. Disponível em: https://rieoei.org/historico/deloslectores/4689Werner.pdf. Acesso em 25 set. 2018.

SILVA, Leandra de Amorim da; MASSAROLLI, Angélica; BUTINARI, Alessandra Regina. Animal combate: um novo instrumento pedagógico para o ensino de ciências e biologia. Revista Educação em Perspectiva, Viçosa, v. 8, n. 3, p. 496-517, 2017. Disponível em:https://periodicos.ufv.br/educacaoemperspectiva/article/view/6980/2832. Acesso em: 10 mar. 2018. 
SEIFFERT-SANTOS, Saulo Cézar; FACHÍN-TÉRAN, Augusto. Possibilidade do uso de analogia e metáfora no processo de ensino-aprendizagem no Ensino de Zoologia no $7^{\mathrm{o}}$ ano do Ensino Fundamental. In: Congresso Norte Nordeste de Ensino de Ciências e Matemática, 8. Anais [...], Boa Vista: UERR, 2009. Boa Vista. 1[CD-ROM].

SEIFFERT-SANTOS, Saulo Cézar; FACHÍN-TÉRAN, Augusto. Perfis e concepções relacionadas à disciplina de ciências naturais sobre o ensino de zoologia dos profissionais do ensino fundamental em Manaus Amazonas, Brasil. In: Encontro de Pesquisa Educacional Norte Nordeste, 20. Anais [...] Manaus: UFAM, 2011. Manaus. 1 [CD-ROM].

TIDON, Rosana; LEWONTIN, Richard. Teaching evolutionary biology. Genetics and Molecular Biology, Ribeirão Preto, v. 27, n. 1, p. 124-131, 2004. Disponível em: http://www.scielo.br/pdf/gmb/v27n1/a21v27n1.pdf. Acesso em: 26 jun. 2018.

ZUANON, Átima Clemente Alves; DINIZ, Raphael Hermano dos Santos; DO NASCIMENTO, Luziane Helena. Construção de jogos didáticos para o ensino de biologia: um recurso para a integração dos alunos a prática docente. Revista Brasileiro de Ensino de Ciência e Tecnologia, Curitiba, v. 3, n. 3, p. 49-59, 2010. Disponível em: https://periodicos.utfpr.edu.br/rbect/article/view/787/606. Acesso em: 26 jun. 2018.

Recebido em: 06 de fevereiro de 2020.

Aprovado em: 21 de abril de 2020. 


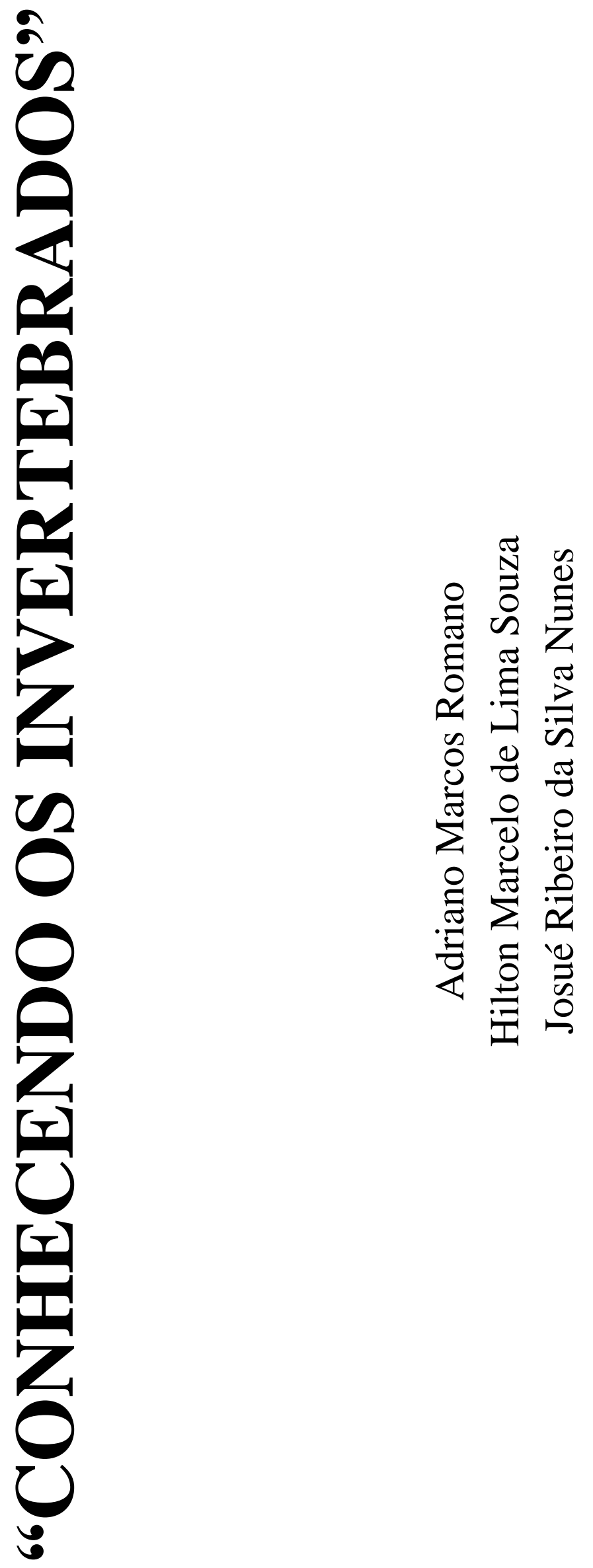



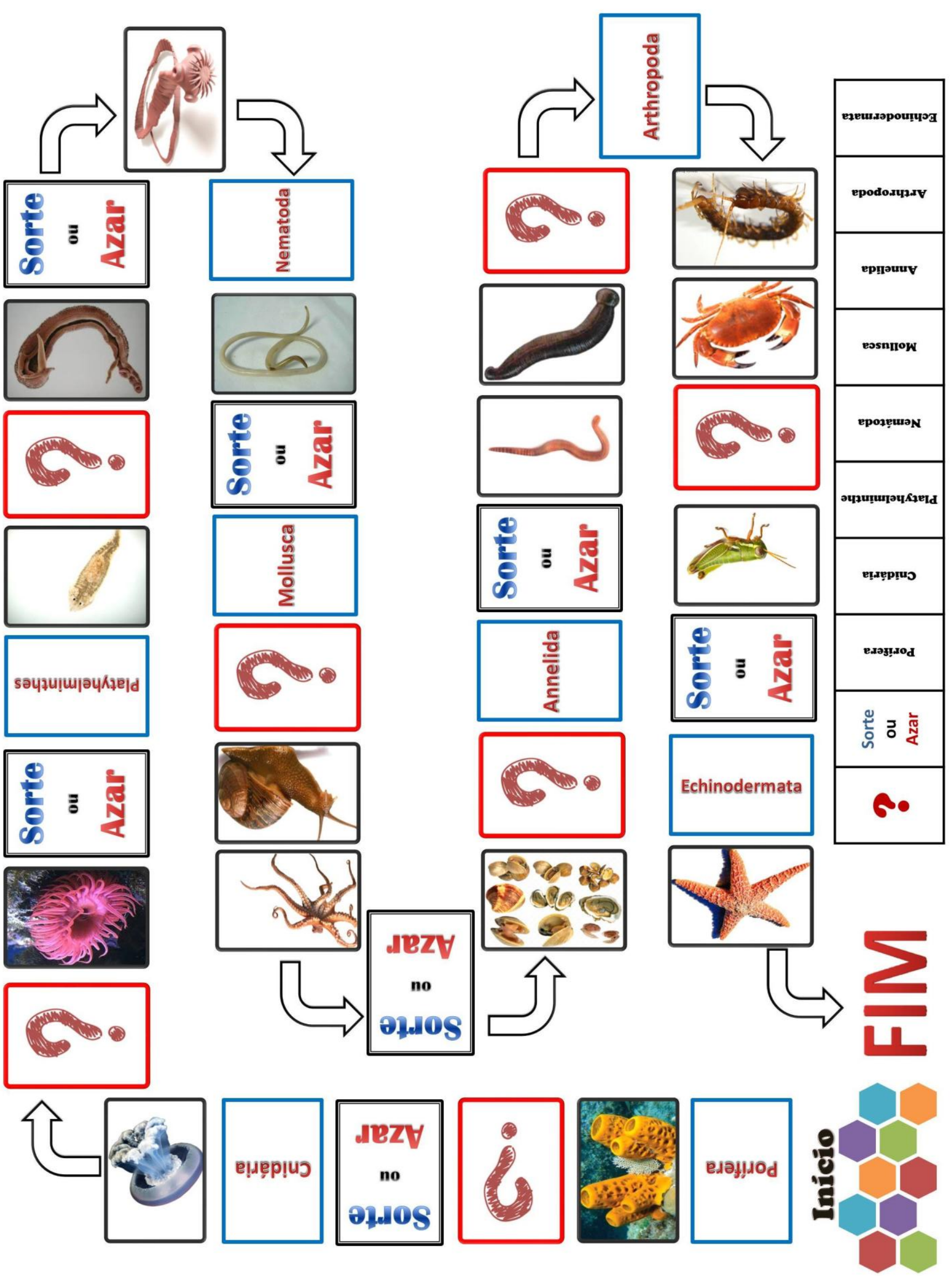


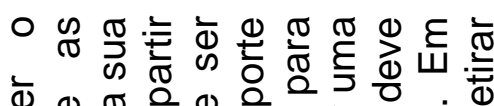

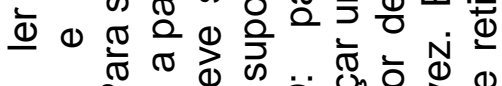

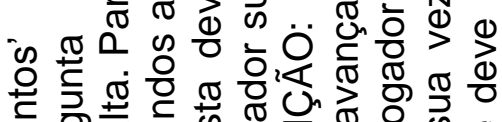
क्ष

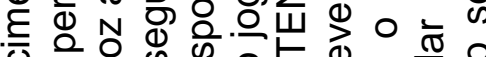

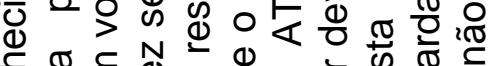

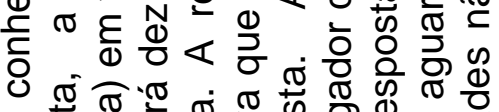
等

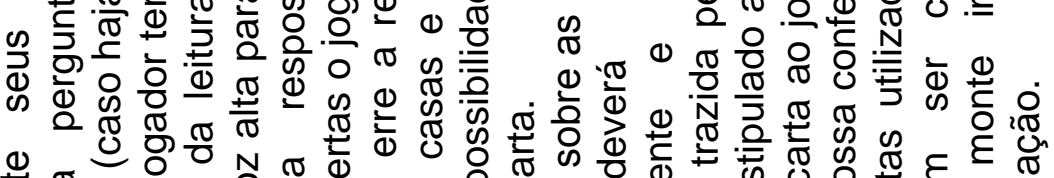

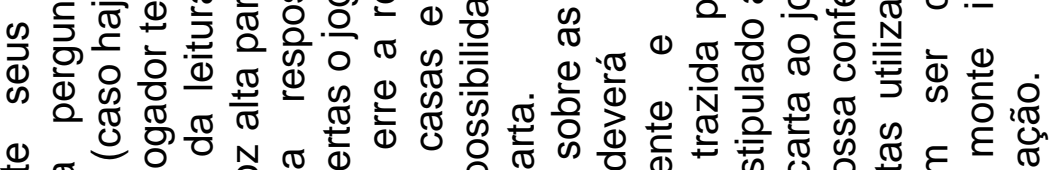

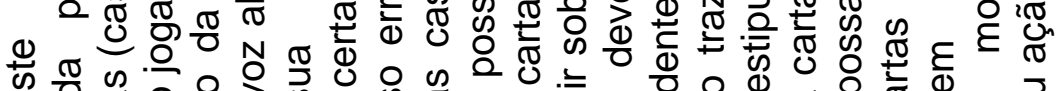

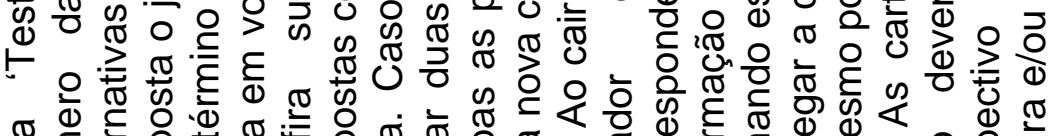

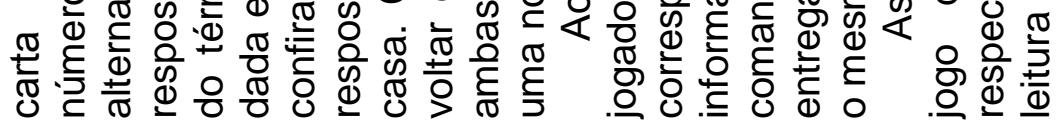

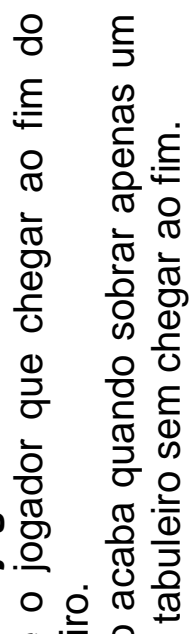

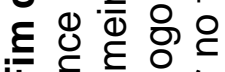
i m

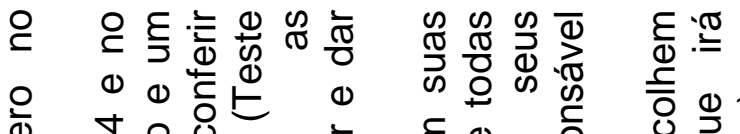

品

宅

흘

๘ 需

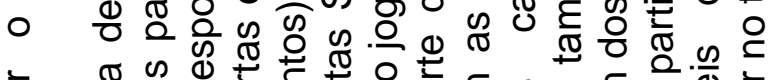

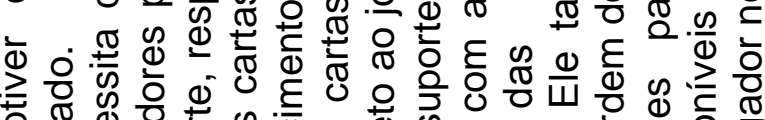

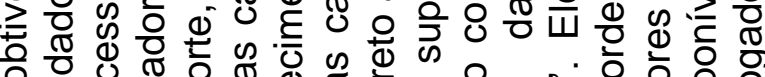

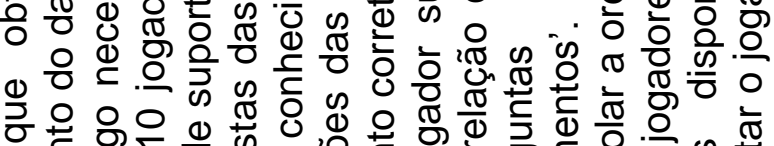

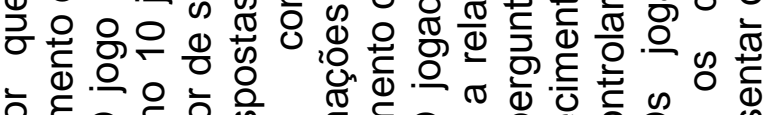

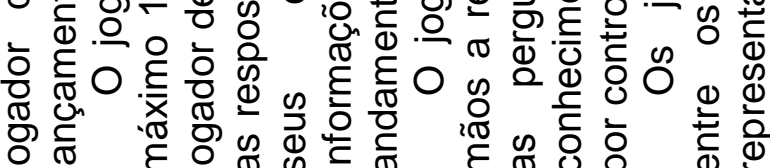
으

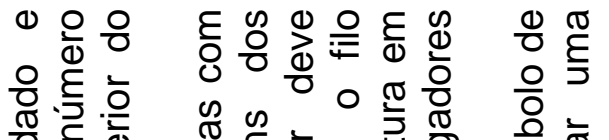

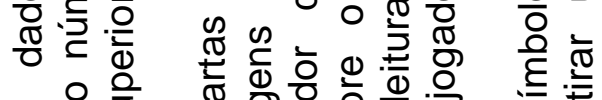
$\circ$ \%

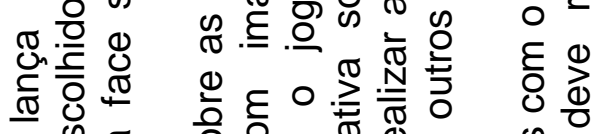

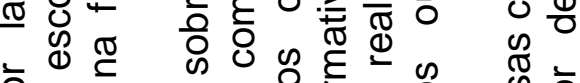

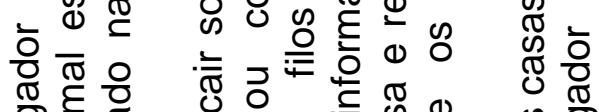
○

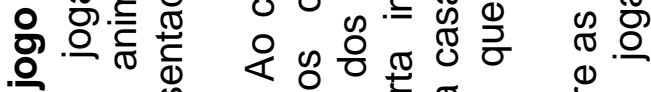
응 응

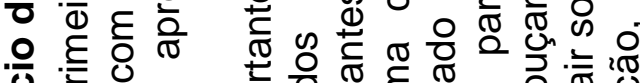
整言

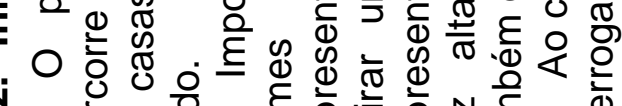

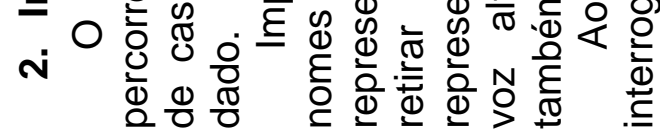

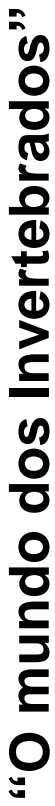

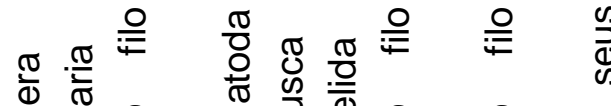
言要

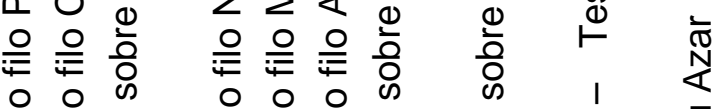

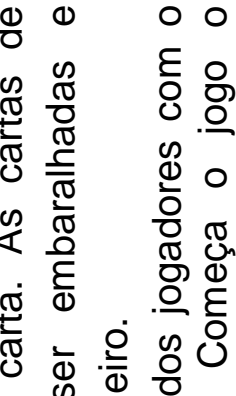

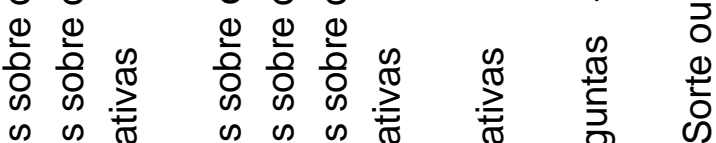

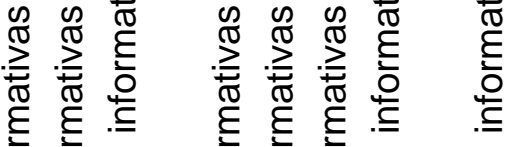

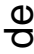
응
$\circ \stackrel{\circ}{\stackrel{0}{2}} \stackrel{\frac{\pi}{0}}{0} \frac{0}{0} \frac{\pi}{0}$

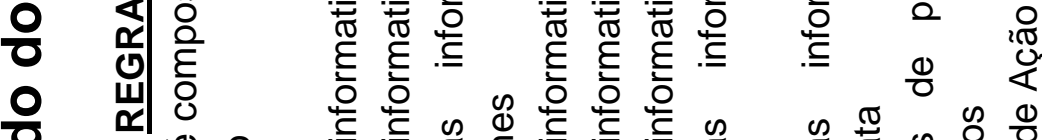

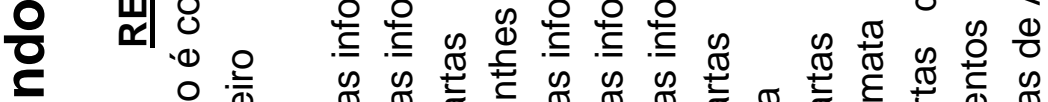

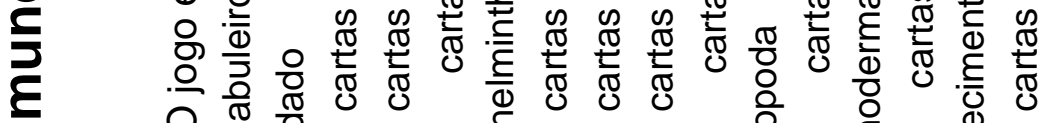

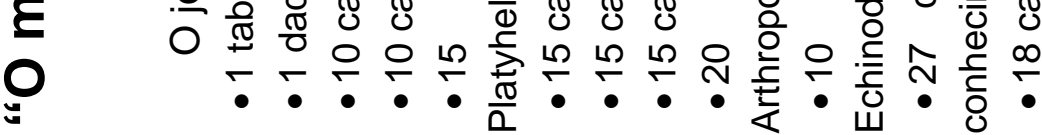

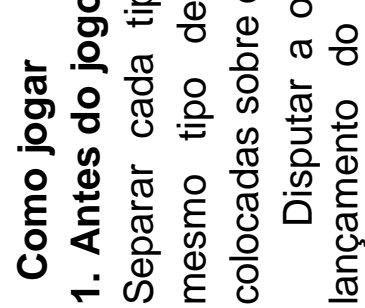



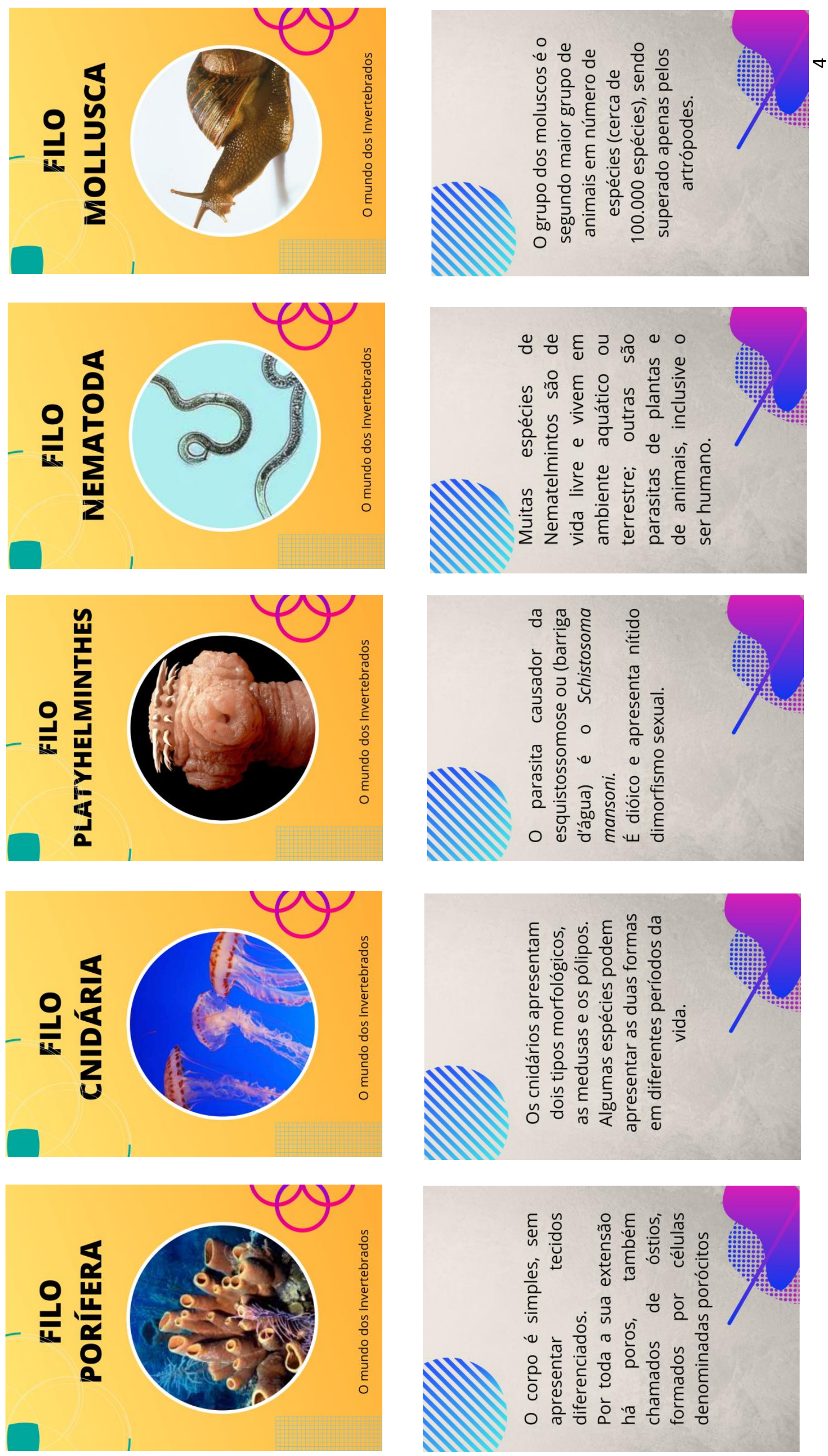

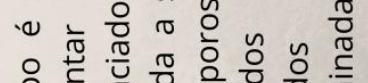

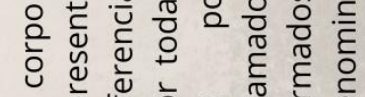

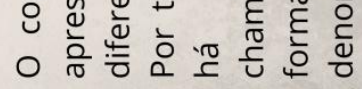



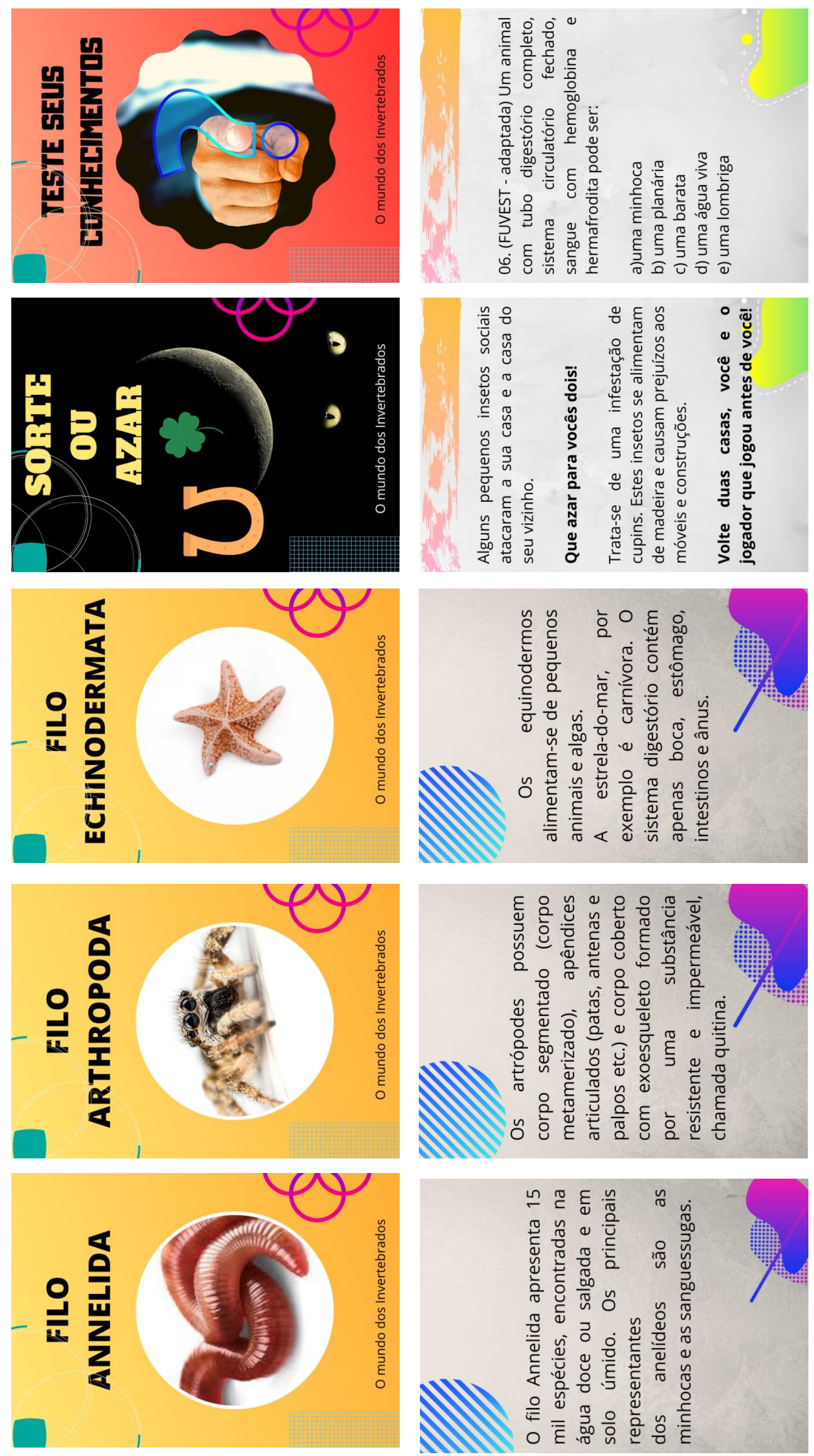

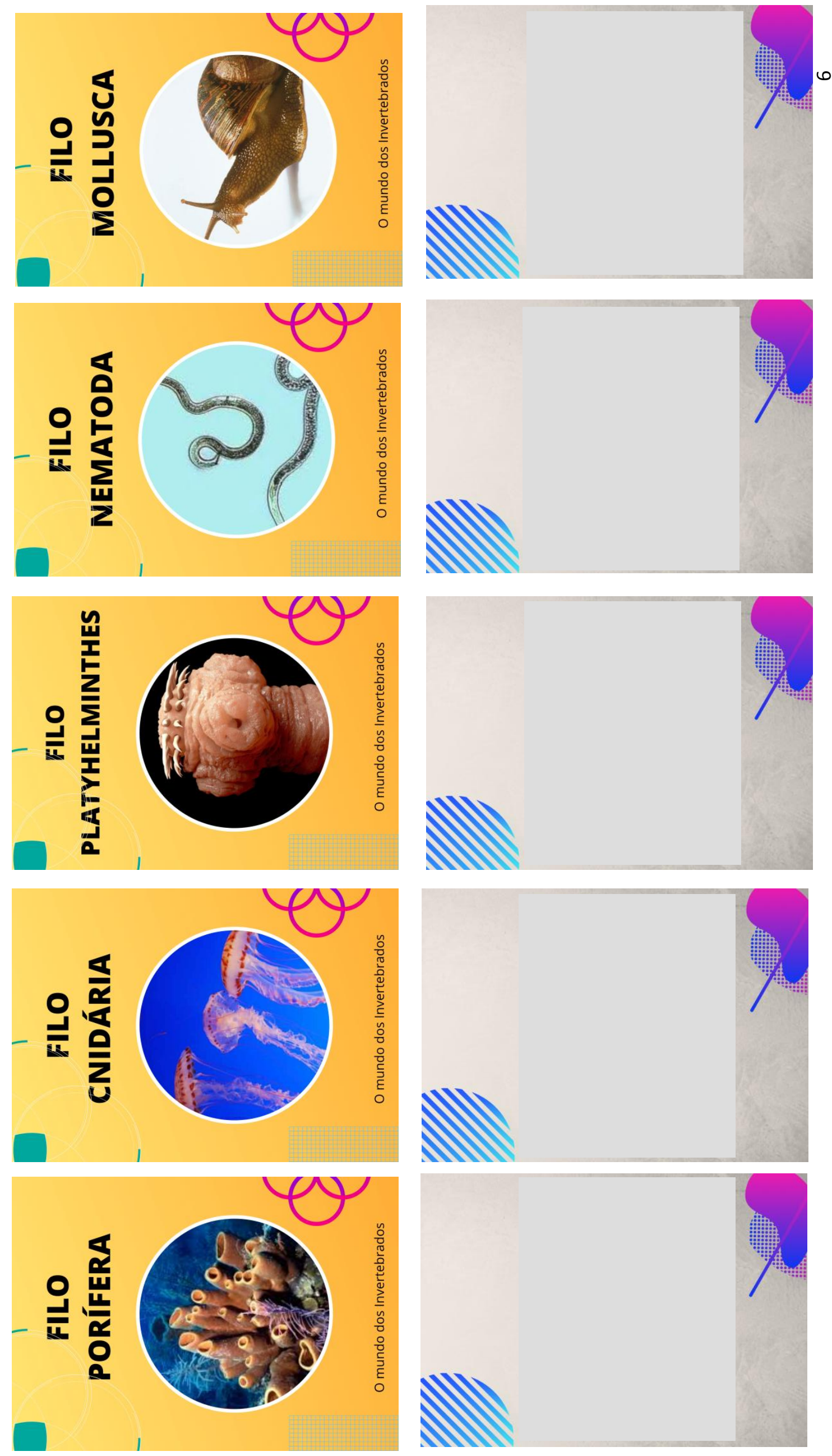

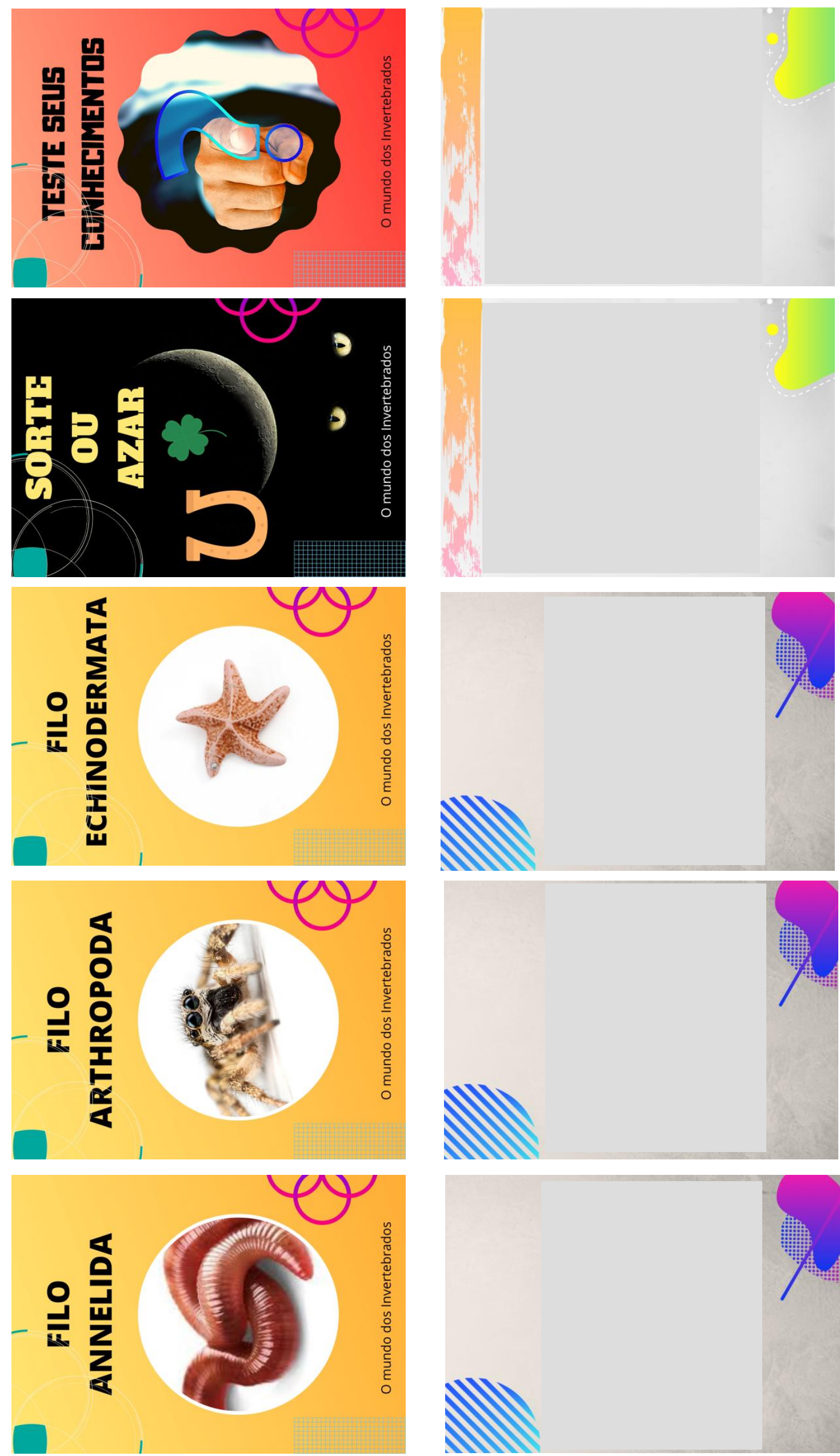